\title{
Pseudo-hermafroditismo masculino em um equino
}

\author{
Male Pseudohermaphroditism in Equine \\ Verônica La Cruz Bueno', Carlos Eduardo Wayne Nogueira', Bianca Lemos dos Santos', \\ Ana Carolina Barreto Coelho', Douglas Pacheco Oliveira', \\ Vera Lucia Bobrowski ${ }^{2}$, Maria da Graça Martino-Roth ${ }^{2} \&$ Bruna da Rosa Curcio' ${ }^{1}$
}

\begin{abstract}
Background: Intersexuality is considered an alteration in the animal development that opposes the characteristics determined by the genetic sex, resulting in an individual with characteristic features of both sexes. The objective of this work is to report a case of male pseudohermaphroditism of a Criollo breed horse referred to the Hospital de Clínicas Veterinárias (HCV) of the Universidade Federal de Pelotas, RS, Brazil. We gather information on the intersexuality diagnostics highlighting cytogenetics as an additional tool to diagnosis.

Case: A Criollo breed horse was attended at the $\mathrm{HCV}$ with the main complaint of morphological anomaly of the external genitalia. The animal presented female external features, characterized by mammal glands and female genitalia. The horse also showed a rudimentary penis-like structure, caudally oriented shrouded by a cutaneous crease similar to a vulva and presented male behavior. The external genitalia was examined but the vaginoscope could not be inserted since the crease ended in a sac, with no openings. Rectal palpation and transrectal ultrasound could not reveal the presence of female gonads. Urethral ultrasound revealed the pelvic urethra and the openings of the male accessory glands. The equine was subjected to hormonal challenge with human chorionic gonadotropin (hCG). First sample presented a testosterone concentration of $20 \mathrm{ng} / \mathrm{dL}$; second sample, on the other hand, presented a testosterone concentration of $60 \mathrm{ng} / \mathrm{dL}$ after the stimulus. The Polimerase Chain Reaction technique revealed absence of gene SRY (sex determiningregion Y). The cytogenetic study was conducted with the lymphocytes obtained from peripherical venous blood. From this, we could verify that the patient was genetically male with karyotype 64 XY. Necropsy showed presence of prepuce and rudimentary penis at the anatomical site of the vulva without scrotum. In the pelvic cavity, a structure similar to a uterine body was observed, with the horns ending at the ovaries anatomical sites, where a structure similar to testicles was found with underdeveloped seminiferous tubules lacking production of spermatozoa and rudimentary epididymis with epididymal ducts coated with primitive stereocilia. Discussion: True hermaphroditism is defined by the presence of ovarian and testicular tissues in the same individual, as separate gonads or combined, as ovotestis. On the other hand, the pseudo-hermaphrodite is an individual with only one gonad, and external genitalia and secondary characteristics of the opposite sex. Urethral endoscopy allowed the visualization of the pelvic urethra and the male sexual glands openings. Following stimulation with hCG, testosterone level increased in $40 \mathrm{ng} / \mathrm{dL}$, evidencing the presence of testicular tissue. Sexual differentiation is determined by the presence or absence of the Y chromosome and by the expression of gene SRY. The animal studied here had karyotype 64 XY and lacked gene SRY, characterizing a condition where testicular differentiation occurred in the absence of gene SRY. It is possible to conclude that clinical evaluation, complementary exams and hormonal analysis allowed the identification of intersexuality. However, only molecular, cytogenetic and histological analyses allowed the definitive diagnosis of male pseudohermaphrodite.
\end{abstract}

Keywords: descriptors: intersex, equine, complementary exams, cytogenetics.

Descritores: intersexo, equino, exames complementares, citogenética. 


\section{INTRODUÇÃO}

A intersexualidade é considerada uma alteração no desenvolvimento, que se contrapõe às características determinadas pelo sexo genético [15], essa e outras anomalias do desenvolvimento do aparelho reprodutor tem sido descritas em várias espécies animais [28]. Essas alterações ocorrem durante a diferenciação sexual do aparelho reprodutor e podem estar relacionadas a fatores genéticos [28]. O processo para a diferenciação sexual no desenvolvimento embrionário e fetal ocorre em três estágios: sexo cromossômico, sexo gonadal e sexo fenotípico e as alteraçõespodem ocorrer em qualquer um deles [6]. O sexo cromossômico é determinado no momento da fertilização, quando o oócito $\mathrm{X}$ é fertilizado por um espermatozoide que carrega o cromossomo X ou Y [32]. Em seguida, é determinado o sexo gonadal, no qual o gene SRY (sex determining region $\mathrm{Y}$ ), localizado no cromossomo $\mathrm{Y}$, é responsável pela masculinização do organismo em desenvolvimento através da diferenciação gonadal em testículos. Se o indivíduo é do sexo genético XX e não possui o gene SRY, a gônada se diferencia em ovário [17]. O sexo fenotípico se desenvolve de forma ativa no macho, devido ao estímulo gerado pela testosterona. Se os hormônios masculinos estão ausentes, ou se os tecidos não respondem a eles, a tendência passiva é de diferenciação em genitália externa feminina [23].

O objetivo deste trabalho foi relatar um caso de pseudo-hermafroditismo masculino, em um equino da raça crioula, encaminhado ao Hospital de Clínicas Veterinárias (HCV) da Universidade Federal de Pelotas (UFPel)-RS, reunindo informações a partir de exames clínicos e morfológicos, avaliação hormonal, análise molecular e evidenciando a citogenética como ferramenta auxiliar para um diagnóstico diferencial.

\section{CASO}

Foi atendido no $\mathrm{HCV}$ um equino, da raça Crioula, com dois anos de idade, pesando $250 \mathrm{~kg}$. A queixa principal foi de anormalidade morfológica da genitália externa. No exame clínico o animal apresentava frequência cardíaca de 40 batimentos por min, frequência respiratória de 16 movimentos por min, temperatura de $38^{\circ} \mathrm{C}$, mucosas róseas, tempo de perfusão capilar de $2 \mathrm{~s}$, normotilidade intestinal em todos os quadrantes, grau de hidratação normal e escore corporal 5 (escala de 1 a 9). Durante a inspeção observou-se a conformação, características morfoló- gicas, comportamento sexual e foi realizada inspeção visual dos órgãos genitais externos. O equino possuía conformação de fêmea, caracterizada pela presença de glândula mamária (Figura 1) e região da genitália feminina. Foi observada estrutura similar a um pênis rudimentar, voltado caudalmente e envolto por uma prega cutânea semelhante a uma vulvana região medial ao períneo (Figura 2). O equino tinha comportamento sexual masculino, apresentando ereção e realizando a monta em fêmeas no estro (Figura 3). No exame ginecológico foi inspecionada a genitália externa, porém não foi possível introduzir o vaginoscópio, pois a prega cutânea que recobria o pênis rudimentar não possuía nenhuma abertura, terminando em fundo de saco. A avaliação do sistema reprodutivo feminino foi realizada através da palpação retal e ultrassonografia transretal, porém não foram observadas estruturas que evidenciassem a presença de gônadas femininas.

Como exame complementar para avaliação do trato urogenital optou-se pela endoscopia realizada com vídeo endoscópio flexível. Após higienização da genitália ambígua, foi realizada a introdução do endoscópio e avaliação da mucosa uretral. O endoscópio foi introduzido pelo orifício da uretra, sendo observada mucosa com coloração rósea pálida e pregas longitudinais. $\mathrm{Na}$ uretra pélvica foram visualizadas em aspecto dorsal, as aberturas das glândulas sexuais anexas masculinas após a introdução de $15 \mathrm{~cm}$ do endoscópio flexível. $\mathrm{Na}$ porção ventral e lateral da uretra, foram identificadas duas fileiras distintas de ductos, que são as aberturas dos ductos das glândulas uretrais. Medialmente a estas encontramos mais duas fileiras paralelas de ductos, sendo identificadas como as aberturas dos ductos das glândulas bulbouretrais. Na sequência, foi observado o colículo seminal, sendo localizadas as aberturas dos ductos das vesículas seminais e ductos deferentes, que se

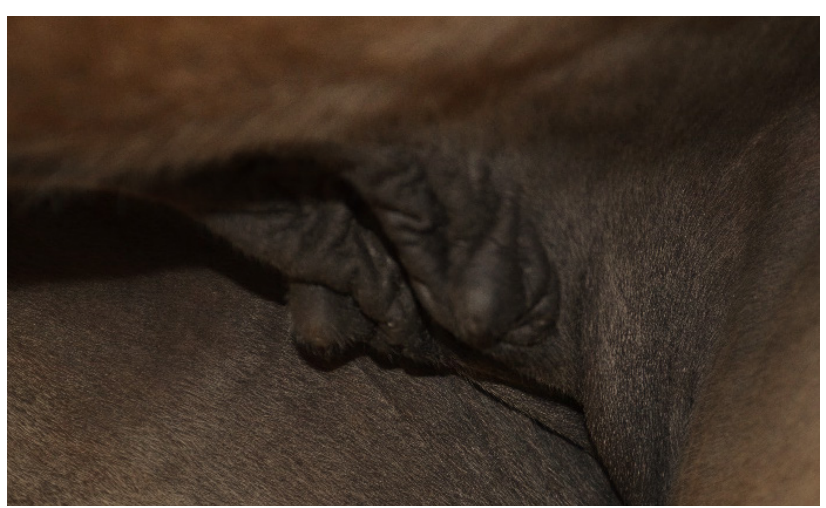

Figura 1. Imagem mostrando o desenvolvimento da glândula mamária de um equino com pseudo-hermafroditismo masculino. 


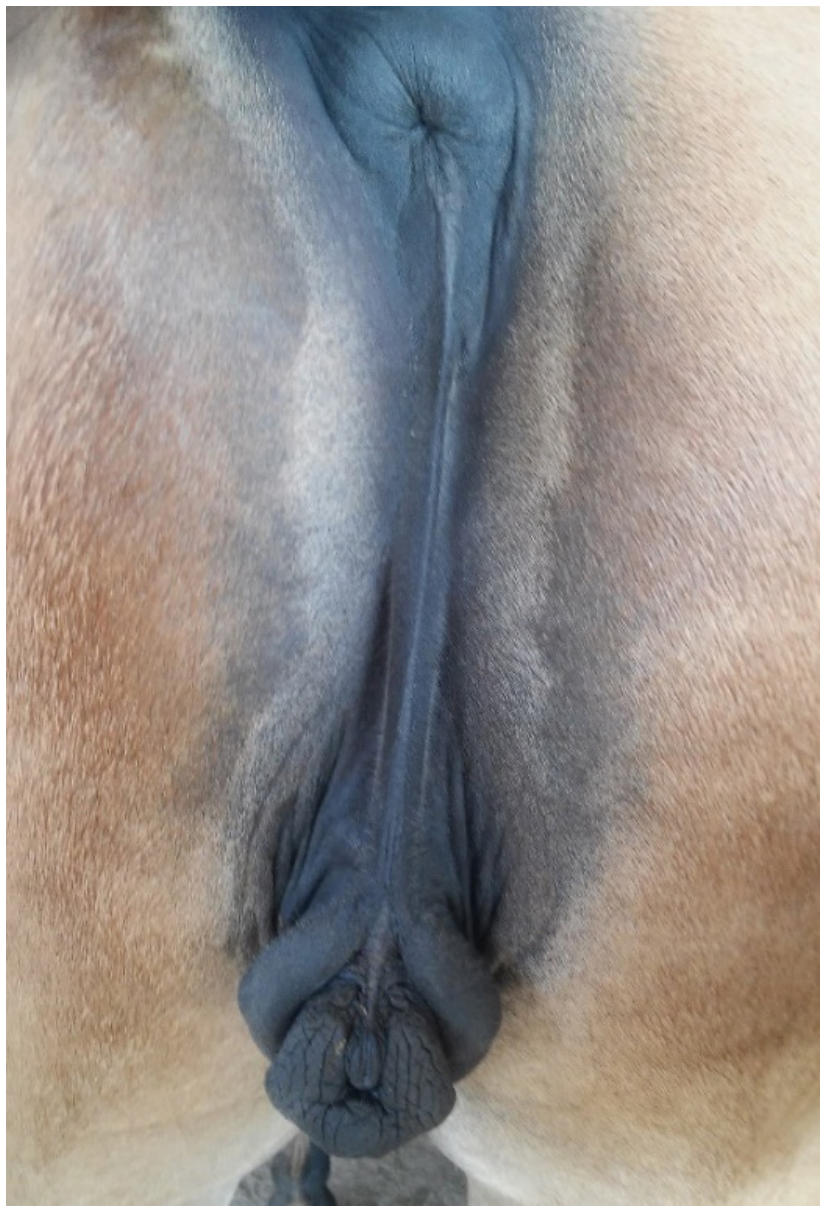

Figura 2. Genitália externa de um equino com pseudo-hermafroditismo masculino, mostrando um pequeno pênis, voltado caudalmente, envolto por uma prega cutânea, na região mediana do períneo.

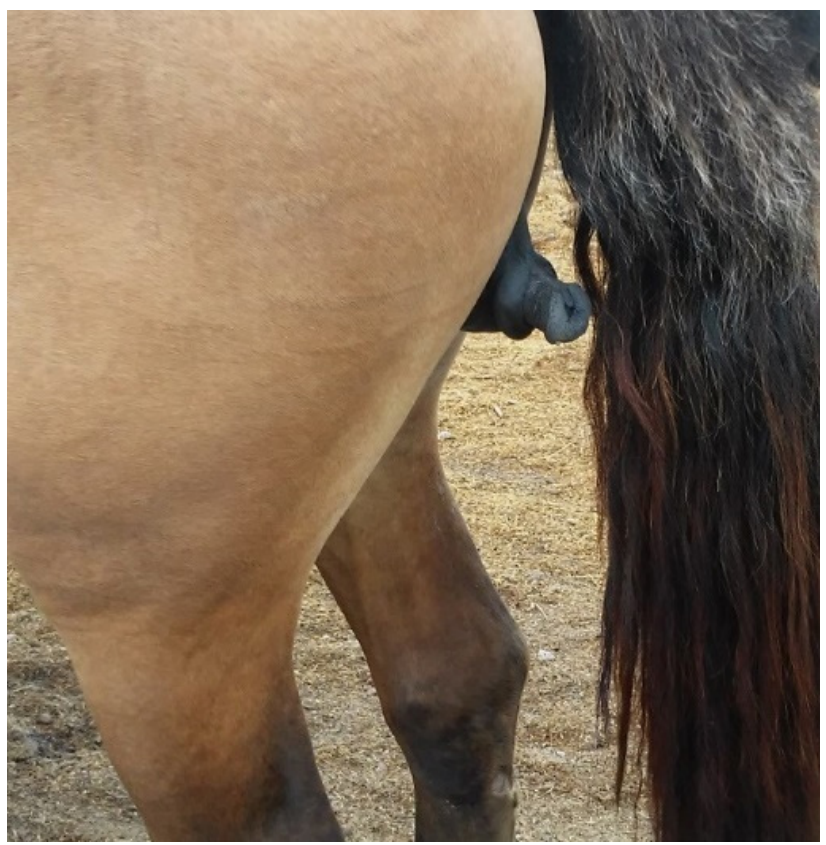

Figura 3. Imagem de um equino com pseudo-hermafroditismo masculino demonstrando comportamento sexual de macho, na presença de éguas em estro. unem e formam o ducto ejaculatório (Figura 4). Seguiu-se a passagem do endoscópio pelo orifício da vesícula seminal, onde foi identificada grande quantidade de plasma seminal (Figura 5).

Para avaliação hormonal realizou-seo teste da síntese de testosterona. $\mathrm{O}$ equino foi submetido a desafio hormonal com gonadotrofina coriônica humana (hCG® ${ }^{\circledR}$ Chorulon $\left.{ }^{\circledR}\right)^{1}$. No primeiro momento foi coletado sangue periférico, após o equino foi estimulado com 10.000 UI de hCG por via endovenosa. Duas horas após a administração de hCG foi realizada segunda coleta sanguínea, o material foi devidamente acondicionado e encaminhado para um laboratório particular de referência na cidade de Pelotas, RS. Na primeira amostra a dosagem hormonal apresentou uma concentração de testosterona de $20 \mathrm{ng} / \mathrm{dL}$ e a segunda amostra, após o estímulo, apresentou concentração de testosterona de $60 \mathrm{ng} / \mathrm{dL}$.

A análise molecular, para a detecção do gene SRY no DNA do equino hermafrodita, foi realizada através da técnica de PCR (Polimerase Chain Reaction). A coleta do sangue periférico foi realizada por punção da veia jugular utilizando sistema (Vacuttaneir ()$^{2}$. O material foi acondicionado e encaminhado ao Laboratório de Biotecnologia da UFPel-RS, onde foi possível comprovar a ausência da região determinante do sexo masculino (SRY).

O estudo citogenético foi realizado a partir do cultivo de linfócitos, obtidos através de sangue venoso periférico [24]. A desnaturação para produção das bandas $G$ foi realizada a partir da imersão da lâmina durante $11 \mathrm{~s}$ em tripsina ${ }^{3}$. As lâminas foram coradas com Giemsa $6 \% \AA^{3}$ por $15 \mathrm{~min}$, lavadas com água destilada, secas em temperatura ambiente, e analisadas em objetiva de imersão (100X). Após a coloração foi possível avaliar numérica e morfologicamente os cromossomos. A técnica de bandeamento G possibilitou estudar estruturalmente as bandas e sub-bandas e identificar as cromátides irmãs. Para a montagem do cariograma, os cromossomos foram alinhados pelo centrômero, dispondo-se os braços curtos para cima e numerando os pares cromossômicos por ordem decrescente do maior para o menor braço curto.

Foram analisadas 20 metáfases, o cariótipo do animal relatado apresentou número diploide normal $2 \mathrm{n}$ = 64 cromossomos. Os cromossomos autossômicos se apresentaram em pares sendo: 7 metacêntricos, 6 submetacêntricos e 18 acrocêntricos. Com relação ao par de cromossomos sexuais, o animal hermafrodita 


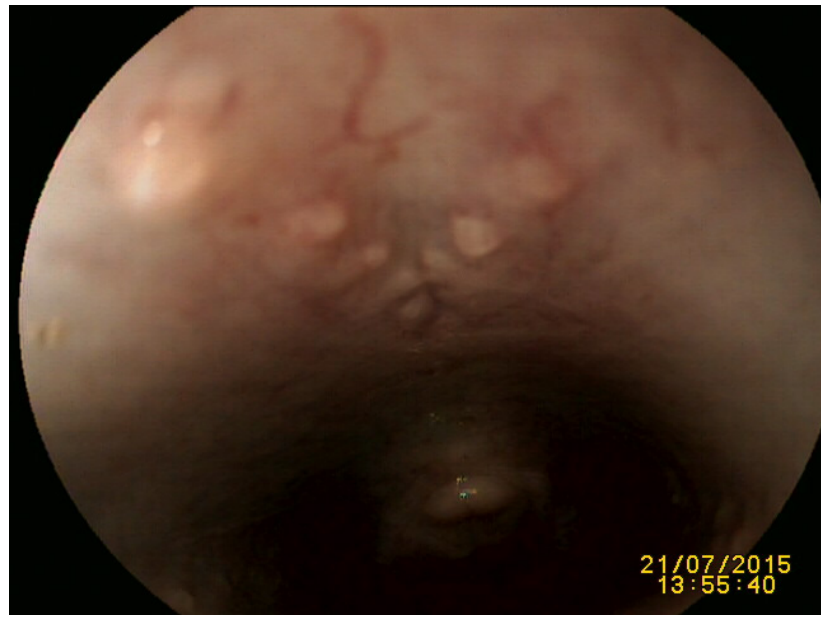

Figura 4. Imagem endoscópica da uretra pélvica de um equino com pseudo-hermafroditismo masculino, mostrando as aberturas das glândulas sexuais anexas.

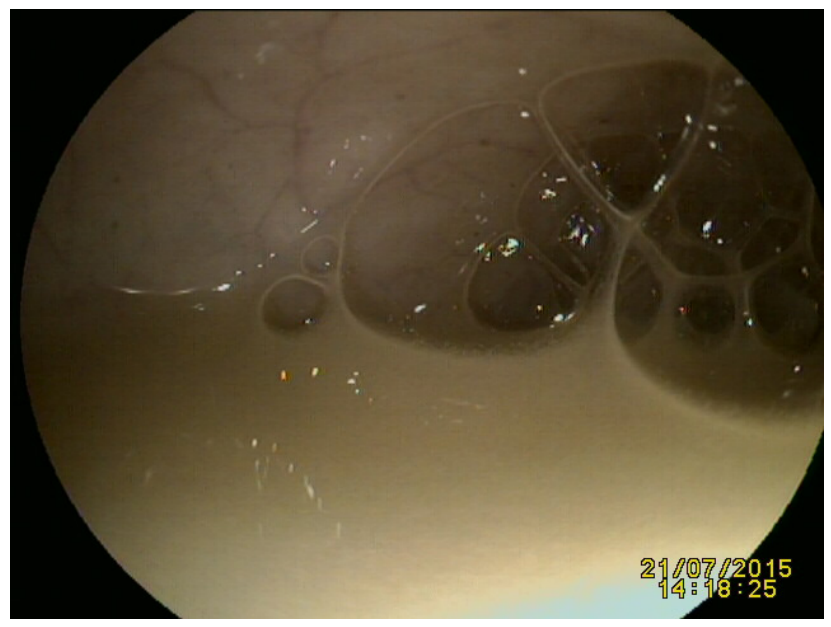

Figura 5. Imagem endoscópica do interior da vesícula seminal, de um equino com pseudo-hermafroditismo masculino, repleta de plasma seminal.

apresentou um cromossomo $\mathrm{X}$ grande na forma submetacêntrica e um cromossomo Y menor na forma submetacêntrica. A partir do estudo citogenético foi possível evidenciar que o paciente relatado é geneticamente macho apresentando cariótipo 64 XY (Figura 6).

Na necropsia verificou-se a presença de prepúcio e pênis rudimentares no local anatômico da vulva, não foi observado escroto. Na abertura da cavidade pélvica havia estrutura similar a um corpo uterino com os cornos que terminavam no local anatômico do ovário (Figura 7).

$\mathrm{Na}$ histologia observou-se útero e trompas uterinas rudimentares. A trompa era formada por células epiteliais organizadas em pregas ramificadas. No local anatômico do ovário havia estrutura similar ao testículo com túbulos seminíferos pouco desenvolvidos, sem produção de espermatozoides, e epidídimo rudimentar com ductos epididimários revestidos por estereocílios primitivos (Figura 8).

\section{DISCUSSÃO}

Baseando-se no exame clínico, na inspeção visual, nos exames complementares, na análise molecular, citogenética e exame histopatológico, pode-se afirmar ser um caso de pseudo-hermafroditismo masculino, pois as características dominantes encontradas eram predominantemente masculinas.

Animais que possuem órgãos genitais com características de ambos os sexos, em função de anomalias no desenvolvimento do sistema reprodutivo, são geralmente classificados como intersexos [24], resultando em uma variedade de fenótipos [14]. Desordens do desenvolvimento genital podem ocorrer em todos os mamíferos, no entanto, o mecanismo que leva à sua ocorrência não está bem esclarecido [11]. Com exceção do Freemartismo bovino, a intersexualidade é considerada uma alteração congênita rara em animais domésticos [26], sendo as espécies mais frequentemente acometidas bovinos, caprinos, ovinos e suínos [1].

Hermafrodita é o indivíduo que apresenta os dois sexos distintos anatômica e funcionalmente. Clinicamente, essa intersexualidade pode ser classificada em

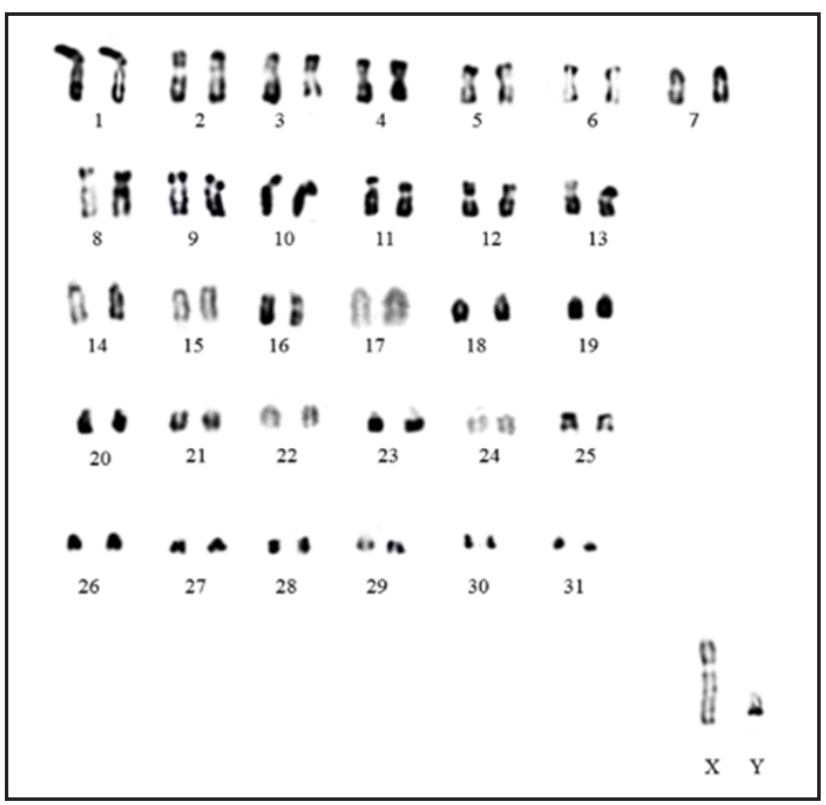

Figura 6. Pareamento cromossômico de um equino com pseudohermafroditismo masculino, apresentando número diploide $2 \mathrm{n}$ = 64 cromossomos. Os 31 pares autossomos (7 metacêntricos, 6 submetacêntricos, 18 acrocêntricos e o par sexual XY (submetacêntrico). [100x]. 


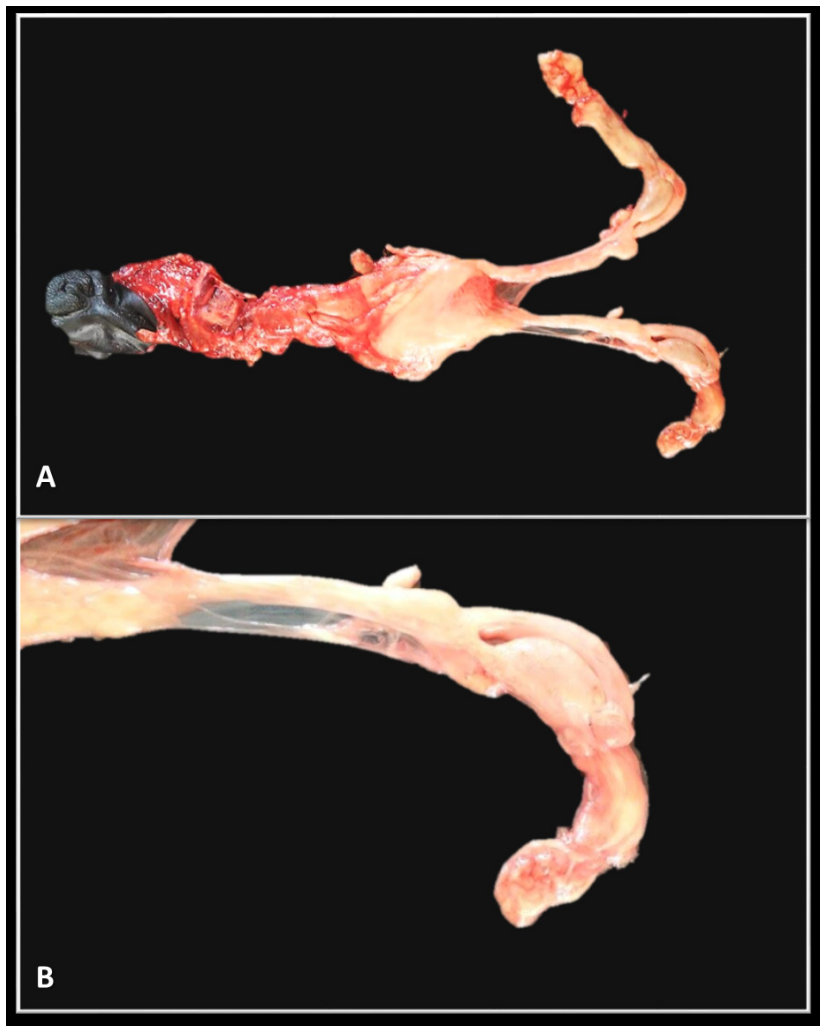

Figura 7. A- Aspecto macroscópico da peça genital, demonstrando presença de pênis anormal em região anatômica da vulva, com presença de glande peniana em porção de clitóris. Segmento de estruturas tubulares, originando trompas uterinas rudimentares, com gônadas de aspecto macroscópico sugestivas de testículos rudimentares. B- Estruturas gonadais, demonstrando disposição morfológica de testículo, com presença de tecido testicular, junto a estrutura epididimária.

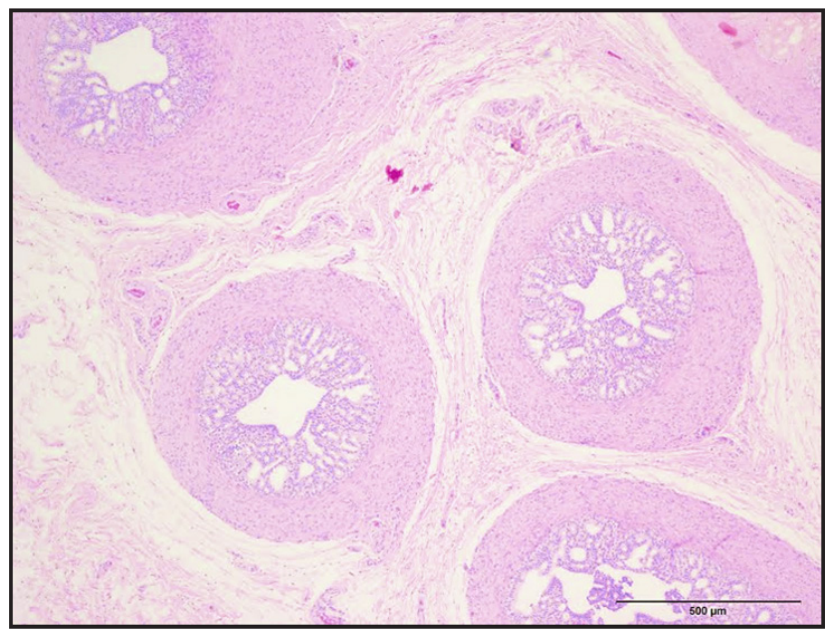

Figura 8. Estruturas tubulares, com arranjo de oviduto, e presença de cílios na região apical das células epiteliais.

hermafroditismo verdadeiro e pseudo-hermafroditismo feminino ou masculino [15]. Hermafroditismo verdadeiro é definido pela presença de tecidos ovariano e testicular no mesmo indivíduo, em gônadas separadas ou em uma só, chamada ovotestis [6]. Durante a vida intrauterina, a presença de tecidos ovariano e testicular, ambos com sua produção hormonal, resultam em diferenciação anormal das genitálias interna e externa [32]. O pseudo-hermafrodita é o indivíduo que apresenta apenas uma das gônadas com características secundárias e genitália externa do outro sexo. Se a gônada presente for um testículo, o animal é pseudo-hermafrodita macho, e caso a gônada seja um ovário, é pseudo-hermafrodita fêmea [15]. Os pseudo-hermafroditas masculinos possuem testículos, mas apresentam também algumas características femininas, como a presença de útero e genitália externa primariamente feminina [7].

As características fenotípicas do equino deste relato eram ambíguas. A partir da endoscopia uretral, foi possível visualizar a uretra pélvica e as aberturas das glândulas sexuais anexas características do gênero masculino. Essas estruturas, originalmente localizamse no aspecto dorsal da uretra e são características do gênero masculino na espécie equina [31]. No presente caso, a uretra do equino possuía $15 \mathrm{~cm}$ de comprimento, sendo menor do que a de equinos machos adultos, uma vez que em um garanhão pode chegar até $100 \mathrm{~cm}$ de comprimento [27].

Do ponto de vista hormonal, frequentemente os hermafroditas apresentam valores de testosterona normais, compatível com a presença de células de Leydig, e hormônio anti-mulleriano detectável, compatível com células de Sertoli funcionais [17]. Para a avaliação da integridade da via sintética de testosterona utilizou-se hCG na dose de 10000UI por via endovenosa, dosando-se os hormônios da via sintética de testosterona, antes e $2 \mathrm{~h}$ após o estímulo [20]. No equino relatado, os níveis de testosterona livre foram de 20 ng/dL inicialmente e $60 \mathrm{ng} / \mathrm{dL} 2 \mathrm{~h}$ após o estímulo. $\mathrm{O}$ valor inicial de testosterona é semelhante ao apresentado por equinos criptorquidas [20]. Após o estímulo com hCG o nível de testosterona teve um acréscimo de 40 ng/dL. A estimulação prévia com hCG através de dosagem de testosterona antes e após o estímulo revelou elevação dos níveis, evidenciando a presença de tecido testicular $[3,21]$

Além do diagnóstico clínico por palpação retal, ultrassonografia, vaginoscopia e uretroscopia nos quais as anomalias facilmente são detectadas [6], o exame genético se faz necessário para que se possa verificar com exatidão a razão pela qual essa intersexualidade ocorre [5]. A investigação citogenética por meio da cultura de linfócitos periféricos e a análise molecu- 
lar de sangue por meio do PCR são métodos muito utilizados e valiosos para o diagnóstico mais preciso das anomalias genéticas responsáveis por essa intersexualidade [33].

$\mathrm{Na}$ análise molecular foi possível constatar que o equino era negativo para presença do gene SRY. A diferenciação gonadal é determinada pela presença ou ausência do cromossomo Y e pela expressão do gene SRY [12]. Este fragmento de DNA determina o sexo do animal [13], através da codificação da proteína TDF (fator de determinação testicular), que induz as gônadas indiferenciadas a transformarem-se em testículos $[9,18]$. Com a ação do TDF, há a atrofia dos ductos de Muller, o desenvolvimento da gônada masculina, a formação de túbulos seminíferos, a formação das células Leydig e a produção de testosterona [10]. As gônadas femininas possuem seu desenvolvimento na ausência desses fatores [16]. A expressão normal do gene SRY durante a vida intrauterina induz as gônadas indiferenciadas a transformarem-se em testículos a partir da diferenciação das células de Sertoli primordiais em células adultas [8].

A cariotipagem é uma importante ferramenta com a qual se caracterizam os cariótipos normais e descobre-se mais sobre as bases fundamentais das anomalias [19]. O avanço da citogenética permitiu a descoberta de que as anormalidades cromossômicas são as principais causas de malformações do trato reprodutivo nos animais domésticos [2]. No presente relato, o estudo citogenético comprovou que o animal era um pseudo-hermafrodita macho com cariótipo $2 \mathrm{n}$ = 64 XY. O pseudo-hermafroditismo masculino é o tipo mais comum de intersexualidade que ocorre nos animais domésticos [5]. O complemento cromossômico sexual dos pseudo-hermafroditas masculinos pode ser $\mathrm{XY}$ ou $\mathrm{XX}$, mas a constituição $\mathrm{XX}$ ocorre frequentemente em suínos [7].

O fato dos testículos não estarem perfeitamente diferenciados revela que esta diferenciação sem a presença do gene SRY não ocorre de forma plena, mas no caso relatado foi suficiente para masculinizar a genitália externa [30].

A importância da realização dessas análises citogenéticas está no fato de que, só assim, é possível realizar o diagnóstico diferencial para outras intersexualidades que apresentam características clínicas semelhantes [22]. Como por exemplo, a Síndrome de Turner equina $(63, \mathrm{X} 0)$ [8], que é uma anomalia caracterizada pela presença de somente um dos cromossomos X que causa infertilidade [19].

A espécie equina está caracterizada por ter uma taxa de alterações cromossômicas muito superior a outras espécies domésticas de produção, valores que podem chegar a $2 \%$ em algumas raças [29], e dentro dessa prevalência é demonstrado que a maioria das alterações ocorre no par cromossômico sexual [4]. Estudos de várias gerações indicam que as malformações genitais e a redução da saúde reprodutiva ocorrem por influência humana na busca de animais de alta produção, indicando um aumento no número de genes responsáveis por estas alterações presentes no concepto devido à consanguinidade [1].

Pode-se concluir que com a avaliação clínica, exames complementares e avaliação hormonal foi possível identificar a presença da intersexualidade no equino. Porém, somente com a avaliação molecular, citogénetica e histológica foi possível chegar a um diagnóstico definitivo de pseudo-hermafrodita masculino.

\section{MANUFACTURERS}

${ }^{1}$ MSD Animal Health. Santiago, Chile.

${ }^{2}$ Vacuplast. Cotia, SP, Brazil.

${ }^{3}$ Vitrocell Embriolife. Campinas, SP. Brazil.

Acknowledgements. Gostaríamos de agradecer ao Dr. ${ }^{\circ}$ Enio Luís Ribeiro Brito.

Declaration of interest. The authors declare no conflict of interest. The authors are responsible for the content and writing of the paper.

\section{REFERENCES}

1 Basrur P.K. \& Basrur V.R. 2004. Genes in genital malformations and male reproductive health. Animal Reproduction. 4(1): 64-85.

2 Basrur P.K. \& Stranzinger G. 2008. Veterinary cytogenetics: past and perspective. Cytogenetic and Genome Research. 120: 11-25. 3 Brochure. 2010. Castration: From Stalion to Gelding. Proceedings of the American Association of Equine Practitioners. [Fonte:<http://www.aaep.org/info/horse-health?publication=705>]. [Accessed online April 2016].

4 Bugno M., Słota E. \& Kościelny M. 2007. Karyotype evaluation among young horse populations in Poland. Schweizer Archiv fur Tierheilkunde. 149(5): 227-232. 
5 Bugno M., Zabek T., Golonka P., Pieńkowska S.A., Schelling C. \& Słota E. 2008. A case of an intersex horse with 63,X/64, XX/65, XX, del karyotype. (New York, USA). Cytogenetic and Genome Research. 120: 123-126.

6 Campbell M. 2004. A case of male pseudohermaphroditism in a horse: Senior seminar paper. (Ithaca, NY). Cornell University College of Veterinary Medicine.10p.

7 Corcini C.D., Leon P.M.M., Rambo G., Santos E.C.S., Varela Filho J.A.S., Moreira F., Fernandes C.G. \& Lucia Jr. T. 2009. Um caso de pseudo-hermafrodita masculino em um suíno. Acta Veterinaria Brasilica. 3(3): 163-165.

8 Coelho E.G.A. \& Oliveira D.A.A. 2008. Testes genéticos na eqüídeo cultura. Revista Brasileira de Zootecnia. 37: 202-205.

9 Cunha J.L., Soardi F.C., Bernardi R.D., Oliveira L.E.C., Benedetti C.E., Guerra Filho J.G., Guerra M.A.T. \& Mello M.P. 2011. The novel p.E89K mutation in the SRY gene inhibits DNA binding and causes the 46,XY disorder of sex development. Brazilian Journal of Medical and Biological Research. 44(4): 361-365.

10 Daminiani D., Dichtchekenian V. \& Setian N. 2000. O enigma da determinação gonadal - O que existe além do cromossomo Y? Arquivos Brasileiros de Endocrinologia \& Metabologia. 44: 248-256.

11 Delfini A., Toniollo G.H. \& Canola J.C. 2007. Pseudo-hermafroditismo masculino em cão da raça American Pit-Bull Terrier. Ciência Animal Brasileira. 8: 333-338.

12 Di Meo G.P., Neglia G., Perucatti A., Genualdo V., Iannuzzi A., Crocco D., Incarnato D., Romano G., Parma P. \& Iannuzzi L. 2009. Numerical sex chromosome aberrations and abnormal sex development in horse and sheep. Sexual Development. 3(6): 329-332.

13 Durval D., Nuvarte S., Hílton K., Manna D. \& Vaê D. 2001. Genitália Ambígua: Diagnóstico Diferencial e Conduta. Arquivos Brasileiros de Endocrinologia \& Metabologia. 45(1): 37-47.

14 Feldman E.C. \& Nelson R.W. 2004. Infertility, associated breeding disorders, and disorders of sexual development. In: Feldman E.C. \& Nelson R.W.(Eds). Canine and Feline Endocrinology and Reproduction. 3rd edn. Philadelphia:WB Saunders, pp.893-898.

15 Grunert E., Birgel E.H., Vale W.G. \& Birgel Junior E.H. 2005. Patologia e clínica da reprodução dos animais domésticos-Ginecologia. 2.ed. São Paulo: Varela, 551p.

16 Han S.H., Yang B.C., Ko M.S., Oh H.S. \& Lee S.S. 2010. Length difference between equine ZFX and ZFY genes and its application for molecular sex determination. Journal of Assisted Reproduction and Genetics. 27: 725-728.

17 Howden K.J. 2004. Androgen insensitivity syndrome in a Thoroughbred mare (64, XY - testicular feminization). Canadian Veterinary Journal. 45: 501-503.

18 Lear T.L. \& McGee R.B. 2012. Disorders of sexual development in the domestic horse, Equus caballus. Sexual Development. 6(1-3): 61-71.

19 Lyle S.K. 2007. Disorders of sexual development in the dog and cat. Theriogenology. 68: 338-343.

20 McCue P.M. \& Ferris A.R. 2016. Formulary and Protocols in Equine Reproduction. Fort Collins: Colorado State University, 18p.

21 McKinnon A., Samper O., Juan C. \& Jonathan F. 1993. Current Therapy in Reproduction Equine. 2nd edn. Louis: Elsevier Saunders, pp.1344-1360

22 Meinecke B., Drögemüller C., Kuiper H., Bürstel D., Wohlsein P., Ebeling S., Wehrend A. \& Meinecke T.S. 2007. A diploid-triploid (60, XX/90, XXY) intersex in a Holstein heifer. Sexual Development. 1: 59-65.

23 Nascimento E.F. \& Santos R.L. 2003. Patologia da reprodução dos animais domésticos. 2.ed. Rio de Janeiro: Guanabara Koogan, pp.15-89.

24 Peyrás S., Anaya G., Bugno P.M., Pawlina K., Membrillo A., Valera M. \& Moreno M.M. 2014. The use of a novel combination of diagnostic molecular and cytogenetic approaches in horses with sexual karyotype abnormalities: A rare case with an abnormal cellular chimerism. Theriogenology. 81(8): 1116-1122

25 Sarafoglou K. \& Ostrer H. 2000. Familial sex reversal: a review. Journal of Clinical Endocrinology and Metabolism. 85: 483-493.

26 Schlafer D.H. \& Miller R.B. 2007. Pathology of the genital system of the non gravid female. In: Grant M.M., Jubb K. \& Palmer's (Eds). Pathology of Domestic Animals. 5th edn. Edinburgh: Saunders Elsevier, pp.431-444.

27 Sobestiansky J. \& Carvalho L.F.O.S. 2007. Malformações. In: Sobestiansky J. \& Barcellos D. (Eds). Doenças dos suínos. Goiânia: Cânone, pp.536-537.

28 Speirs V.C. 1999. Sistema Reprodutor do Macho. In: Exame clínico de equinos. Porto Alegre: Artmed, pp.233-236.

29 Ticianelli J.S., Oliveira B.M.M., Zogno M.A., Arruda R.P. \& Celeghini. E.C.C. 2011. Intersexo e outras anomalias do desenvolvimento do aparelho reprodutor nos animais domésticos e o auxílio da citogenética para o diagnóstico. Revista Brasileira de Reprodução Animal. 35(1): 26-32. 
30 Villagómez D.A.F., Lear T.L., Chenier T., Lee S., McGee R.B., Cahill J.R., Foster A., Reyes E., St. John E. \& King W.A. 2011. Equine disorders of sexual development in 17 mares including XX, SRY-negative, XY, SRY-negative and XY, SRY-positive genotypes. Sexual Development. 5(1): 16-25.

31 Waldridge B. 2010. Disorders of the Urinary System. In. Reed S.M., Baylyand W.M. \& Sellon D.C. (Eds). Equine Internal Medicine. 3rd edn. Saint Louis: Saunders Elsevier, pp.1221-1224.

32 Zenteno-Ruiz J.C., Kofman A. S. \& Méndez J.P. 2001. 46,XX sex reversal. Archives of Medical Research. 32: 559-566. 33 Zogno M.A., Barnabe V.H. \& Barnabe R.C. 2000. Animal cytogenetics: some modifications in the peripheral blood lymphocyte culture technique. Brazilian Journal of Morphological Sciences. 17: 23-25. 